\title{
ENTRE A EFEMERIDADE DAS STORIES E A MEMÓRIA DA ESCOLA
}

\author{
Joana Dourado França de Souza \\ Edvaldo Souza Couto \\ Maria Helena Bonilla $(*)$
}

\section{INTRODUÇÃO}

Em qualquer tempo e lugar, hoje, as pessoas conversam, compartilham informações, narram suas vidas cotidianas e contingentes por meio de tecnologias digitais. Com dispositivos móveis, smartphones e tablets, sempre ao alcance das mãos, praticamente tudo, para elas, torna-se suscetível de registros, de trocas, de interações, especialmente, em sites e aplicativos de redes sociais. E os jovens, neste contexto, são protagonistas, pois, naturalmente, participam destas redes, transitam, constantemente, entre os ambientes virtuais e presenciais durante o correr de suas vidas, desde tenra idade.

No Brasil, $83 \%$ dos jovens ${ }^{1}$ com idade inferior a 18 anos utilizam as tecnologias móveis para se conectar à internet. 64\% deles acessam as redes sociais digitais logo após acordar ${ }^{2}$ e mantêm-se conectados ao longo do dia. A conexão ubíqua proporcionada por estes aparelhos mobiliza ininterruptas interações por meio de textos, imagens, vídeos e áudios nos diversos ambientes virtuais disponíveis e produz, desta forma, tais percentuais. Esse status always on é utilizado por uma expressiva quantidade de crianças e adolescentes que tem suas vidas organizadas pelos smartphones, tablets e seus respectivos aplicativos.

Neste contexto, uma funcionalidade de redes sociais digitais tem atraído muitas das interações destes jovens e, por isso, diariamente, proporciona milhares de publicações no Brasil e

\footnotetext{
${ }^{(*)}$ Joana Dourado F. Souza. Mestre em educação pela Universidade Federal da Bahia (UFBA) e professora na pósgraduação da Universidade Salvador (UNIFACS). E-mail: joana.dourado@yahoo.com.br.

Edvaldo Souza Couto, Doutor em educação pela Universidade Estadual de Campinas (UNICAMP), professor titular na Faculdade de Educação, na Universidade Federal da Bahia (UFBA). É um dos coordenadores do Grupo de Pesquisa Educação, Comunicação e Tecnologias (GEC). É bolsista de Produtividade em Pesquisa do CNPq. Email: edvaldo@ufba.br

Maria Helena Bonilla é doutora em educação pela Universidade Federal da Bahia (UFBA), professora associada na Faculdade de Educação da UFBA e líder do Grupo de Pesquisa Educação, Comunicação e Tecnologias (GEC). Email: bonilla@ufba.br.

1 Pesquisa: $80 \%$ da população brasileira entre 9 e 17 anos usam a internet < http://agenciabrasil.ebc.com.br/pesquisa-einovacao/noticia/2016-10/pesquisa-80-da-populacao-brasileira-entre-9-e-17-anos-usam> Acesso em: 01 abr. 2018

2 Jovens brasileiros são os mais dependentes das redes sociais < http://www.correio24horas.com.br/noticia/nid/jovensbrasileiros-sao-os-mais-dependentes-das-redes-sociais/ > Acesso em: 01 abr. 2018.
} 
em todo o mundo, as Stories, um recurso no qual as postagens são armazenadas durante o prazo máximo de 24 horas na memória dos aplicativos das redes sociais Facebook, Instagram, WhatsApp e Snapchat. O apagamento das Stories corresponde ao principal atributo de sua funcionalidade, porque provoca um fluxo ininterrupto de publicações sem rastros que é condizente com a velocidade vertiginosa e a liquidez do mundo contemporâneo, no qual o trânsito de novidades é permanente.

Rastrear o passado das interações perde a relevância em um contexto em que o mais importante é estar presente, literalmente fluir junto ao movimento contínuo das trocas e compartilhamentos em redes. Em conexões constantes vive-se um agora perene e os jovens seguem o fluxo desse devir, estão imersos nesse universo de aplicativos e redes. Por isso, apresentam subjetividades, modos de ser e estar condizentes com este cenário.

Em contrapartida, outro ambiente frequentado pela juventude, a escola, possui características antagônicas às das redes sociais digitais. As atividades proporcionadas por essa instituição educativa necessitam de lentidão, de repetição, de permanência em registros, em memória, exigem uma solidez no que diz respeito à postura de todos os seus integrantes, notadamente, os estudantes, contrapondo-se, desta forma, à liquidez das redes.

Muitos estudos têm como escopo possíveis transformações no contexto escolar para entrar em sintonia com o mundo contemporâneo de dispositivos móveis, aplicativos e redes, e, por conseguinte, tornar a instituição mais atrativa para os estudantes. Vale pensar, entretanto, se este movimento atual de tecnologias digitais, de fluxo permanente e veloz de interações e de memória de curto prazo condiz com as práticas escolares. Desse modo, o objetivo do artigo é problematizar se é possível uma realidade escolar em concordância com a lógica dos aplicativos de redes sociais e suas atuais funcionalidades. O método utilizado para este estudo foi o da pesquisa qualitativa de caráter bibliográfico. Para tanto, foi realizada uma revisão de literatura fundamentada em conceitos e discussões sobre memória, cultura escolar, modernidade líquida e cibercultura aplicada à educação, notadamente, ao que diz respeito às redes sociais digitais em torno da denominada era da mobilidade. 


\section{MOBILIDADE, APLICATIVOS DE REDES SOCIAIS E STORIES}

Depois que os celulares deixaram de ser apenas telefones móveis e passaram a ser também aparelhos inteligentes, smartphones, os aplicativos3 (apps) tornaram-se os seus principais atrativos. Há uma infinidade de apps disponíveis para download nestes dispositivos, em sua maioria gratuitos, com uma grande diversidade de finalidades, desde o auxílio em tarefas domésticas, esportivas e profissionais até lembretes durante todo o dia para beber a quantidade necessária de água, por exemplo. Os aplicativos de redes sociais, neste contexto, são os mais utilizados pois possibilitam interações entre pessoas por meio de textos, vídeos, fotos e áudios em qualquer lugar e a qualquer momento. E uma específica funcionalidade destes apps que tem se destacado atualmente é a função Stories.

Hoje, as principais redes e mídias sociais dispõem da funcionalidade Stories. Este recurso surgiu em setembro de 2011 como principal formato de interação do aplicativo Snapchat. Nesta rede, o participante publica imagens, textos, GIFs e vídeos que são exibidos em até 10 segundos nas telas dos respectivos contatos e permanecem na memória do aplicativo durante o prazo máximo de 24 horas. Com esta dinâmica de postagens efêmeras, rapidamente o programa se popularizou em todo o mundo e alcançou a marca de 150 milhões de usuários ativos por dia4. Esta ascensão chamou a atenção de Mark Zuckerberg, atual dono das mídias sociais Facebook, Instagram e Whatsapp, que, primeiramente, em 2012, tentou comprar o aplicativo Snapchat5. Evan Spiegel, dono do app, recusou a proposta, então, Zuckerberg acrescentou a função Stories, semelhante à do Snapchat, no Instagram em agosto de 20166, no WhatsApp em fevereiro de 2017 e no Facebook em março de $2017 .^{7}$

Para Lemos e Lévy (2010, p. 62), os espaços virtuais estão cada vez mais associados aos espaços concretos das cidades por meio das tecnologias móveis e seus respectivos aplicativos. O indivíduo torna-se um "nômade informacional em deslocamento", porque transita pelo físico, pelas

\footnotetext{
${ }^{3}$ Softwares desenvolvidos para serem utilizados em aparelhos móveis como smartphones e tablets.

${ }^{4}$ Snapchat ultrapassa Twitter em número de usuários ativos por dia < http://g1.globo.com/tecnologia/noticia/2016/06/snapchatultrapassa-twitter-em-numero-de-usuarios-ativos-por-dia.html > Acesso em: 01 de abr. 2018.

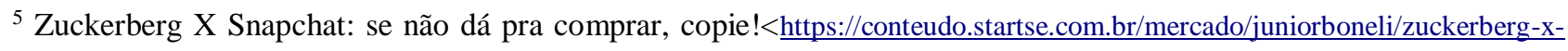
snapchat-se-nao-da-pra-comprar-copie/> Acesso em: 01 de abr. 2018.

${ }^{6}$ Instagram Stories já tem mais usuários do que Snapchat <https://exame.abril.com.br/tecnologia/instagram-stories-mostralado-implacavel-de-facebook-e-zuckerberg/> Acesso em: 01 de abr. 2018.

${ }^{7}$ Facebook ganha função Stories e fica cada vez mais perto do Snapchat <https://canaltech.com.br/redes-sociais/facebook-ganhafuncao-stories-e-fica-cada-vez-mais-perto-do-snapchat-91272/> Acesso em: 01 de abr. 2018.
} 
cidades, conectado à rede onde ele também se move, compartilhando em ambos espaços informações, produções, momentos, acontecimentos, etc.

Para Santaella (2010; 2011), são chamados de espaços intersticiais, quando os espaços físicos se misturam, se hibridizam com espaços virtuais, compondo, assim, espaços conectados. Em tais lugares as fronteiras são difusas, são borradas, isto é, o indivíduo conectado percorre, movimenta-se, interage, ao mesmo tempo nos dois contextos, e o fluxo de informação do meio digital se expande para o ambiente físico, e vice-versa, dissipando os limites entre os dois. Esta perspectiva de Santaella segue o mesmo viés de Souza e Silva (2006), que, no entanto, apresenta outro nome para esta dinâmica. Para esta autora são nomeados espaços híbridos os que são criados a partir das constantes conexões entre o virtual e o físico no movimento dos acontecimentos das vidas dos indivíduos e dos meios urbanos.

As Stories só podem ser registradas por meio de dispositivos móveis para captar o movimento dos interagentes, o acontecer de suas vidas cotidianas e contingentes, seguindo, assim, a perspectiva de mobilidade entre espaços físicos e virtuais. A sequência de publicações neste recurso tem como objetivo contar a história de um dia, uma narrativa efêmera que logo é substituída pela história do dia seguinte. São registros do presente, fugazes, instantâneos, cuja intenção é exibir o devir da vida. Consoante Santaella,

No emaranhamento, mobilidade, fluidez, no ir vir que constitui a carne do mundo urbano contemporâneo, mundo prenhe de presenças fortuitas, encontros acidentais, fugidios, efêmero, a dispersão das cenas nas suas formas flutuantes de aparição convida tão só e apenas ao testemunho descompromissado do momento, antes que o instante se apague para sempre. (SANTAELLA, 2011, p. 395)

É no emaranhado da dinâmica que as Stories acontecem, no híbrido entre o urbano e o virtual e na liquidez da contemporaneidade. Esta liquidez do mundo atual é caracterizada pela constante mudança, pelo caráter provisório de tudo ou de quase tudo. Para Bauman (2014), houve uma transição da modernidade sólida para a líquida, isto é, as instâncias sociais que estruturam as vidas das pessoas, como casamento e emprego, por exemplo, não mantêm suas configurações por muito tempo, são transformadas, desestruturadas e reorganizadas constantemente, diferente da suposta solidez de outrora na qual a permanência, a manutenção de tudo que compõem a vida social, era basilar. A liquidez é o cenário volátil, então, propício para fluxos ininterruptos de Stories nos aplicativos de redes sociais.

Gardner e Davis (2013) afirmam que crianças e adolescentes de hoje, situados nesta modernidade líquida, que já nasceram em tempos de conexões ubíquas e pervasivas e, 
possivelmente, não conheceram outra realidade, têm suas vidas organizadas pelos aplicativos de tecnologias móveis. O desenvolvimento psicológico, o comportamento social deles são orientados por estes programas. Estes jovens, por exemplo, buscam validação para suas personalidades e estilos de vida por meio dos compartilhamentos, das interações nos apps. Outra marcante característica apresentada por esses autores, para a denominada geração $a p p$, é o imediatismo. Isto é, os aplicativos influenciam a juventude a ter um comportamento imediatista, pois atendem instantaneamente seus desejos a partir de simples e breves toques nas telas touch screen. A funcionalidade Stories, notoriamente, está plenamente imersa nesta realidade por fomentar também tais qualidades e modos na geração app.

Neste cenário atual de conexões ininterruptas, de efemeridades, muitos jovens publicam continuamente conteúdos em redes sociais, criam, compartilham, interagem e se sentem cada vez mais estimulados a participar desta dinâmica de produção incessante e efervescente. De outro lado, o ambiente escolar, espaço que os jovens também frequentam diariamente, ainda é caracterizado pela modernidade sólida. Nele a condição é de permanência, de repetição, de memória das ações e das práticas. Ou seja, a escola possui um caráter diametralmente oposto ao do contexto de tecnologias móveis, aplicativos e Stories.

\section{ESCOLA E MEMÓRIA}

Tradicionalmente, os professores registram os acontecimentos da sala de aula em diários de classe. Registram os comportamentos dos alunos, os conteúdos apresentados, as ausências e as presenças dos participantes, dentre outras anotações. Os estudantes, munidos dos seus cadernos e materiais didáticos, transcrevem os apontamentos feitos pelos professores na lousa, fazem exercícios, estudam para avaliações, registram, para consultas posteriores, as suas trajetórias de estudos. E a maioria desses acontecimentos diários, durante os anos letivos, são guardados nos arquivos das secretarias e coordenações escolares para permanecerem à disposição enquanto patrimônio destas instituições.

Estes registros cotidianos, por serem tão detalhados, ao decorrer do tempo, tornam-se documentos que contam a história da escola e servem como objeto de pesquisa para historiadores.

Os arquivos escolares têm emergido como temática recorrente no campo da história da educação. O potencial histórico dos acervos institucionais e pessoais contendo documentação escolar como atas, livros com registros sobre a vida escolar dos alunos, termos de exame e aproveitamento escolar, relatórios de inspetores, manuais pedagógicos, documentos produzidos 
por alunos e professores e fotografias vêm mobilizando pesquisadores da área (KIRCHNER, 2009, p. 01)

A produção em âmbito escolar é feita para permanecer, para tornar-se memória, acervo disponível para posteriores consultas, para análises pormenorizadas que podem dispor de tempo extenso, pois a existência de registros que atravessam a história indicam uma garantia de que podem ser vistos e revistos quantas vezes forem necessárias.

O papel, até tempos recentes, era o principal suporte da escola moderna. Documentos elaborados de forma artesanal, manuscritos, muitas vezes rubricados por quem compunha o topo da hierarquia escolar e/ou quem era responsável pela produção deles caracterizavam, e de certa forma ainda caracterizam, as maneiras de construir os registros desta instituição. Como descreve Werle,

A distribuição no papel, a sequência de colunas, a caligrafia e a rubrica/ carimbo eram as tecnologias do documento. O espaço bem planejado, a disciplina e perfeição no traçado; a disposição das informações no papel considerando tanto o espaço deixado em branco como os espaços escritos; a forma, portanto, além das informações constituíam o documento como único. Não havia como reproduzi-lo. Assim sua localização era também única, na própria instituição escolar. (WERLE, 2002, p. 80)

Todos os detalhes dos registros denunciavam, e ainda denunciam, a intenção de permanência. Os cabeçalhos das provas, das apostilas, com espaços em branco para posterior preenchimento pelos alunos e professores, os espaços em linhas para anotações e respostas, apontavam e apontam o caráter único destes documentos, e o propósito de que foram e ainda são elaborados para compor a memória da escola, mesmo após o domínio do uso das impressoras para reprodução.

Atualmente, a rotina de registros escolares tem incorporado os dispositivos tecnológicos digitais, todavia a permanência, a memória, enquanto escopo destes arquivos subsistem. Parte da memória escolar, hoje, é digital, materiais didáticos podem ser acessados por meio de sites e ambientes virtuais de aprendizagens, informações sobre os estudantes, dados sobre a instituição, dentre outros. Como afirma Werle, a respeito dos boletins escolares,

[...] de um documento confeccionado em gráfica ou impresso em mimeógrafo, em papel cuja espessura era fator importante de durabilidade e resistência ao longo do ano letivo, o boletim escolar está sendo disponibilizado na página web das escolas; como documento digital, sob a forma de bytes visualizado em pixels. (WERLE, 2002, p.78)

Entretanto, mesmo com a mudança de suporte, a perspectiva de que tais documentos compõem a memória, a história das instituições, é mantida. Isto é, não há um prazo de duração para 
os registros, digitais ou analógicos, eles devem permanecer disponíveis enquanto acervo por tempo indeterminado.

Em um dos contos do livro "Ficções", Jorge Luís Borges (2007, pp 1024) apresenta o personagem Funes, o memorioso. Após um acidente, Funes adquiriu uma memória "prodigiosa", isto é, ele não esquecia de absolutamente nada, tudo que vivia, cada minucia, cada detalhe era guardado por completo em sua memória. "Essas lembranças não eram simples; cada imagem visual estava ligada a sensações musculares, térmicas etc. Podia reconstituir todos os sonhos, todos os entressonhos. Duas ou três vezes tinha reconstituído um dia inteiro." O personagem necessitava de um dia inteiro para rememorar tudo o que tinha vivido em um dia anterior. Por isso, Funes não conseguia pensar, pois o pensamento exige generalizações, abstrações, esquecimentos, o que para ele era impossível já que sua mente era feita de detalhes quase imediatos. Uma ficção irreal que expõe a plena preservação da memória como um excesso que imobiliza pensamentos e ações.

Neste sentido, Chartier e Chartier (2016) afirmam que o movimento de preservação da memória corresponde a uma preocupação histórica do ser humano, desde os tempos de predominância da memória oral, de ritos e mitos e, depois, da memória escrita, de livros, de acervos e de bibliotecas. Essa preocupação existia (e ainda existe), sobretudo, por conta do desejo de conservação do legado do homem. No entanto, era necessária uma seleção do que devia ser guardado em detrimento do que se julgava apto a ser esquecido devido às limitações dos suportes para os registros e dos regimes de poder de cada época, consoante estes autores, diferente do que se tem hoje, tecnologias digitais que podem alcançar uma plena memória semelhante à de Funes. Porém, o prodigioso meio digital não provoca paralisia por excesso de memória, pelo contrário, possibilita uma abstração em relação à preservação e até o apagamento por meio de Stories. Ou seja, uma valorização dos fluxos de informações, porque, na perspectiva da modernidade líquida, a fluidez contínua de novidades é mais importante.

Por outro lado, o cotidiano escolar, suas práticas, rotinas e atividades ainda são pautadas pela lógica da memória escrita, analógica e situada na modernidade sólida. Não apenas no que concerne à conservação de registros, de documentos, de livros e cadernos, mas a toda a sua dinâmica desenvolvida em processos de ensino e aprendizagens. Os processos de ensinoaprendizagem, através de aulas e disciplinas, que ocorrem durante um ou dois turnos diários ao longo de um ano letivo, ou melhor, ao longo de quatorze anos letivos 8 , transcorrem de forma repetitiva, lenta e gradual durante este extenso tempo. As práticas escolares são feitas para serem

\footnotetext{
${ }^{8} \mathrm{O}$ tempo de duração da escolaridade, no Brasil, do ensino infantil ao ensino médio, é de 14 anos.
} 
longevas, para durar, para transcender o tempo do seu acontecimento, para permanecer, primordialmente, nas memórias. Há, desta forma, um predomínio da memória, que, em muitos momentos, priva os participantes da instituição escolar de criar, de abstrair e até mesmo de pensar em função do excesso de memorização, algo semelhante ao infortúnio do personagem Funes.

Contudo, não é possível, para a escola, fugir do que acontece na contemporaneidade. Smartphones, aplicativos e redes sociais frequentam as salas de aula diariamente a despeito de várias negações e de proibições. Como afirmam Moreira e Januário (2014, p. 68), "não podemos escamotear o fato das redes sociais serem o habitat das gerações que, atualmente, recebemos nas nossas escolas" e que estas gerações preferem o fluxo produtivo dos meios digitais em detrimento da memorização escolar, situação que gera uma série de tensões no cotidiano escolar, tensões que necessitam ser explicitadas, analisadas, buscando alternativas que vão além do proibir, controlar. Esse contexto delineia a necessidade de diálogo entre estas duas realidades.

\section{A ESCOLA E A EFEMERIDADE DAS REDES SOCIAIS}

A todo momento, alunos, em posse de seus dispositivos móveis, fotografam as anotações em quadros, feitas por professores, e colocam de lado os seus cadernos. Em grupos do aplicativo WhatsApp, circulam avisos, articulam-se atividades, trocam-se informações, conteúdos referentes às práticas escolares e Stories narram o cotidiano dos estudantes na escola. Estes são alguns exemplos de como as tecnologias móveis e suas funcionalidades estão presentes na instituição escolar, independente da lógica discordante que ainda predomina nela.

Nos aplicativos de redes sociais há avalanches de informações, de narrativas a todo momento. Os interagentes que usufruem destes recursos produzem e publicam conteúdos continuamente, seguindo o fluxo de novidades constantes que caracteriza esta conjuntura. Expõem, nesta dinâmica, com breves textos, imagens, GIFs e vídeos, um potencial ativo, criativo e interativo. Os jovens, protagonistas deste contexto, são os que mais criam e compartilham, por isso, assumem, nestas redes, posturas participativas e engajadas, diferentes das que apresentam nas escolas, geralmente passivas e desestimuladas. Para Souza e Couto (2016, p. 34), a instituição escolar e os professores "podem se transformar através do fluxo de intensas e efêmeras trocas das redes sociais, em processos de ensino-aprendizagem mais interativos, participativos, colaborativos e atrativos para os jovens que vivem intensamente as tecnologias digitais".

Nesse sentido, a funcionalidade Stories, especificamente, pode potencializar ainda mais essa realidade, já que além de propiciar ampla participação, este recurso fomenta publicações mais 
espontâneas e desinibidas da juventude. O pudor de se expor dá lugar à criatividade, à liberdade, pois não há preocupação com o registro que pode constranger no futuro. E nesse contexto de fluidez criativa, no qual se evidencia a autoria das crianças e adolescentes, a memória deixa de ser tão importante. Consoante Couto e Souza (2017, p. 168), "é preciso em algumas situações específicas, abrir mão dos registros tradicionais, afinal apagar, desaparecer e esquecer também são dimensões importantes do ensinar e aprender, são dimensões importantes das relações humanas, do viver em fluxo".

Em contrapartida, a volatilidade, a efemeridade contemporânea unida à ascensão da imagem em detrimento do texto escrito, de certa maneira, limitam a capacidade de leitura e de escrita de crianças e de adolescentes. Isto é, o processo solitário, lento e silencioso do letramento, primordial nas instituições escolares, não é propiciado nas redes. Leitura e escrita exigem tempo extenso, repetição, disciplina e, notadamente, acesso à memória, ao legado humano em acervos, em bibliotecas e afins. Consoante Sibilia,

Ao ler, estudar ou escrever como propõe o dispositivo escolar, por exemplo, experimenta-se um tempo cumulativo, linear e ascendente: cada momento requer uma etapa anterior que the dê sentido e coerência, como um avanço gradativo que se enquadra na lógica racional do progresso. Os meios audiovisuais e interativos, ao contrário, solicitam e incitam outras disposições corporais e subjetivas, bem distintas daquelas que são postas em prática pela leitura e a escrita. (SIBILIA, 2012, p. 90)

Desta forma, os jovens precisam do letramento proporcionado pela escola para ler e escrever nos meios analógicos e digitais. Este processo de ensino - aprendizagem pode se valer das tecnologias, em especial da hipertextualidade e da plasticidade que o virtual proporciona para se desenvolver melhor e de maneira mais atual, porém a lógica que norteia a construção deste saber é a mesma e acontece, sobretudo, na escola.

Habilidades e competências fundamentais para o mundo contemporâneo são desenvolvidas e/ou potencializadas no ambiente escolar e nas redes e mídias digitais, fato que denuncia a necessidade da instituição escolar de legitimar, de introduzir, formal e expressivamente, nas suas práticas o que já está presente, de maneira informal e espontânea, em seu cotidiano. O que não significa a superação do dispositivo escolar, mas uma atualização a partir da aceitação e da valorização dos dispositivos móveis, aplicativos e funcionalidades que os acompanham e que, sobretudo, formam crianças e adolescentes diariamente. 


\section{CONSIDERAÇÕES FINAIS}

Os espaços formativos se multiplicam na atualidade, principalmente, por meio das tecnologias móveis. Sempre ao alcance das mãos, os aparelhos inteligentes e seus aplicativos proporcionam produção e circulação incessante de diferentes saberes e, por isso, educam a juventude, diariamente, assim como a escola, espaço formal para esta finalidade. Os jovens que vivenciam intensamente a cultura digital são os mesmos que estão na escola e, de certo modo, contribuem para uma cultura escolar em rede. A escola se renova e inova com tecnologias conectivas por meio das dinâmicas entre preservação e dissolução de memórias, de saberes. Assim como se renova e inova com seus jovens inquietos e entusiasmados, que experimentam e criam recursos para continuar produzindo soluções criativas para a vida pessoal e escolar nos fluxos dos acontecimentos.

A discussão sobre a efemeridade dos tempos atuais, simbolizada pelo recurso Stories, e a memória da escola, problematizadas nesse artigo, permitem diversas conclusões das quais destacam-se três. A primeira é que os aplicativos de redes sociais e respectivas funcionalidades, além de compor o principal habitat de crianças e de adolescentes, possibilitam desenvolvimento de habilidades e construção de conhecimentos significativos para o mundo contemporâneo, sobretudo, por conta do perfil volátil de suas interações. A fluidez que pauta esta conjuntura propicia produções instantâneas, objetivas e criativas que, por conseguinte, promovem o potencial autoral, notadamente, de jovens. Esse potencial autoral é um fator de inovação para a escola, pois, na cibercultura, não mais se reproduz saberes. O importante é, nos fluxos da rede, remixar criar e difundir conhecimentos de modo colaborativo.

A segunda conclusão é que não se trata de um dualismo. Não existe, de um lado, a escola tradicional e obsoleta e, de outro, a fascinante experiência fluida das conectividades. A cibercultura não é a exclusão de uma experiência em função de outra, mas as misturas, as mixagens, os embaralhamentos de fronteiras. Vivemos entre as memórias que permanecem e que as se dissolvem, deslizam e rapidamente somem das telas. O letramento digital é um dos exemplos de que muitos processos de ensino-aprendizagem requerem uma simbiose entre o formato longevo, linear e gradativo, onde e quando ele for preciso, associado aos deslizamentos efêmeros que nos fascinam.

E a terceira conclusão é que as realidades em simbiose são fundamentais para a formação dos estudantes contemporâneos. É por isso que a escola integra as tecnologias digitais, as redes sociais digitais e a lógica que as compõe, às suas atividades rotineiras. Onde essa simbiose ainda é 
restrita é preciso incorporar plenamente a dinâmica, a volatilidade e a conectividade porque o potencial criativo proporcionado pelos meios digitais e respectivas funcionalidades é imprescindível e pode, inclusive, atualizar e melhorar substancialmente as atividades escolares tradicionais.

Desta forma, a escola se hibridiza à fluidez, às efemeridades da contemporaneidade. Ela transforma, repensa, reconfigura suas dinâmicas, suas perspectivas. Trata-se de um hibridismo, uma combinação de lento e veloz, em igualdade de importância, entre o permanente e o provisório, a instantaneidade e a memória, o sólido e o líquido, o que é perene e o que desliza na magia do instante. O hibridismo de sentidos entre tradição e inovação faz parte do conjunto dos desafios humanos e escolares na cibercultura. 


\section{REFERÊNCIAS}

BAUMAN, Z. Tempos líquidos. 1.ed. Rio de Janeiro: Zahar, 2007. 119p.

BAUMAN, Z. 44 cartas do mundo líquido moderno. 1. ed. Rio de Janeiro: Zahar, 2011. 226p.

BAUMAN, Z. Vigilância líquida. 1. ed. Rio de Janeiro: Zahar, 2014. 159p.

BORGES, J. L. Ficções. 1. ed. São Paulo: Companhia das Letras, 2007. 176p.

CHARTIER, R.; CHARTIER, A. Novas tecnologias - ler e escrever, aprender e apagar. In: ROSING, T. M. K. (Org.). Literatura e identidade na era da mobilidade. 1. ed. Passo Fundo: Editora Universidade de Passo Fundo, 2016. p. 5987.

COUTO, E.; SOUZA, J. Whatsapp com função Stories: ensinar e aprender na magia do instante. In: PORTO, C.; OLIVEIRA, K.; CHAGAS. A. Whatsapp e Educação: entre mensagens, imagens e sons. 1. ed. Ilhéus: Editora UESC, Salvador: EDUFBA, 2017. p. 155-172.

GARDNER, H; DAVIS; K. The App Generation: How Today's Youth Navigate Identity, Intimacy, and Imagination in a Digital World. 1.ed. EUA: Yale University Press, 2013. 272p.

KIRCHNER, C. A. S. M. O caderno de alunos e professores como produto da cultura escolar. In: CONGRESSO DE ENSINO E PESQUISA DE HISTÓRIA DA EDUCAÇÃO EM MINAS GERAIS. 5, 2009, Montes Claros. Anais... Montes Claros: Unimontes, 2009. p. 1-11. Disponível em: <https://slidex.tips/queue/o-caderno-de-alunos-e-professorescomo-produto-da-cultura-escolar?\&queue $\mathrm{id}=-1 \& \mathrm{v}=1522241450 \& \mathrm{u}=\mathrm{MTg} 3 \mathrm{Ljk} 0 \mathrm{Lj}$ I3LjE2Mw> Acesso em: 28 mar. 2018.

LEMOS, A.; LÉVY, P. O futuro da internet: em direção a uma ciberdemocracia. 2. ed. São Paulo: Paulus, 2010. 258p.

MOREIRA, J. A.; JANUÁRIO, S. Redes sociais e educação: reflexões acerca do Facebook enquanto espaço de aprendizagem. In: PORTO, C.; SANTOS, E. (Org.). Facebook e educação: publicar, curtir, compartilhar. Campina Grande: EDUEPB, 2014. p. 67-84.

REBOUÇAS, C. S.; MENESES, J. E. O. Snapchat: o imediatismo imagético e os laços afetivos.In: CONGRESSO BRASILEIRO DE CIÊNCIAS DA COMUNICAÇÃO. 39, 2016, São Paulo. Anais... São Paulo, Faculdade Cásper Líbero, 2016. p. 1-12. Disponível em: <http://portalintercom.org.br/anais/nacional2016/resumos/R11-3056-1.pdf > . Acesso em: 28 mar. 2018.

SANTAELLA, L. Linguagens líquidas na era da mobilidade. 2. ed. São Paulo: Paulus, 2011. 468p.

SANTAELLA, L.; e LEMOS, R. Redes sociais digitais: a cognição cognitiva do Twitter. 1. ed. São Paulo: Paulus, 2010. 137p.

SIBILIA, P. Redes ou Paredes: A escola em tempos de dispersão. 1. ed. Rio de Janeiro: Contraponto, 2012. 222p.

SOUZA E SILVA, A. From cyber to hybrid: Mobile technologies as interfaces of hybrid spaces. Space and culture, v. 9, n. 3, p. 261-278, 2006. Disponível em: <https://tvdigital.files.wordpress.com/2008/09/mobile-2006-adrianasilva.pdf > Acesso em: 28 mar. 2018.

SOUZA, J.; COUTO, E. Snapchat: viver e aprender em meio a mensagens autodestrutivas. In: COUTO, E.,PORTO,C; SANTOS, E. App-learning: experiências de pesquisa e formação. 1. ed. Salvador: EDUFBA, 2016. p. 23-37.

WERLE, F. O. C. Documentos escolares: impactos das novas tecnologias. História da Educação v.6., n.11, 2002. p. 120 Disponível em: <http://seer.ufrgs.br/asphe/article/view/30600 > Acesso em: 28 mar. 2018. 
Resumo: O artigo analisa o descompasso entre as efemeridades da contemporaneidade, simbolizadas pelas Stories, publicações disponíveis durante 24 horas em redes e mídias sociais digitais e a memória da escola. O principal argumento é que a divergência entre estes dois contextos provoca tensões e tornam o cotidiano escolar pouco atrativo para jovens que, hoje, têm suas vidas organizadas por tecnologias móveis e seus aplicativos. O método utilizado foi o da pesquisa qualitativa de caráter bibliográfico. $\mathrm{O}$ estudo foi fundamentado por investigações sobre cultura escolar, modernidade líquida e cibercultura aplicada à educação. $\mathrm{O}$ artigo conclui que tanto a liquidez quanto a memória possuem características fundamentais para as práticas educativas, por isso podem ser combinadas no cotidiano escolar.

Palavras-chave: Tecnologia Educacional; Memória e Stories; Cultura Escolar.

\section{BETWEEEN STORIES'S CELERITY AND SCHOOL MEMORIES}

Abstract: This article analyses the diferences between school memories and contemporaneity's celerity simbolyzed by Stories, digital publications avaliable during 24 hours in social networks. The main argument is that the divergence between these two contexts provokes tensions and make everyday school life unattractive to young people who have their lives organized by mobile technologies and their applications. The method used was qualitative research in a bibliographic way. The study was based on research about school culture, net modernity and cyberculture applied to education. The article concludes that both liquidity and memory have fundamental characteristics for educational practices, so they can be used combined in daily school life.

Key words: Educational Technology; Memory and Stories; School Culture.

\section{ENTRE LA EFEMERIDAD DE LAS STORIES Y LA MEMORIA DE LA ESCUELA}

Resumen: El artículo analiza el descompás entre lo efímero de la contemporaneidad, simbolizado por las Stories, publicaciones disponibles por solo 24 horas, en redes y medios sociales digitales y la memoria de la escuela. El principal argumento es que la divergencia entre estos dos contextos, provoca tensiones y hacen del cotidiano escolar poco atractivo para los jóvenes, que hoy tienen sus vidas organizadas por las tecnologías móviles y sus aplicaciones. El método utilizado corresponde a la investigación cualitativa de carácter bibliográfico. El estudio fue fundamentado por investigaciones sobre cultura escolar, modernidad líquida y cibercultura aplicada a la educación. El artículo concluye que tanto la liquidez como la memoria poseen características fundamentales para las prácticas educativas, por lo que pueden ser combinadas en el cotidiano escolar.

Palabras clave: Tecnología Educativa; Memoria y Stories ; Cultura Escolar. 